\section{Violência contra crianças e adolescentes: questão social, questão de saúde}

\section{Violence against children and adolescents: a social and a health problem}

Maria Cecília de Souza Minayo 1

1 Fundação Oswaldo Cruz

Presidência, Av. Brasil, 4365, Pavilhão Mourisco, $1^{\circ}$. andar,

Manguinhos, Rio de Janeiro, Rio de Janeiro, Brasil, CEP 21.045.900

\begin{abstract}
History shows that from primitive times until the present age violence against children has been a social and cultural phenomenon of great relevance. The forms of violence, the cruelest and the most subtle, differ within societies. In Brazil, we distinguish a structural violence which is strongest among children who work and those who live on the streets or who are confined in closed institutions, and a social violence which is more vividly expressed in domestic violence; a delinquent violence where the children are both victims and actors. The juvenile and children's statute represents an important instrument through which society and the State, recognizing the characteristics of both entities, can try to dominate the forms of violence affecting their growth and development and thus their social development.

Key words Violence, Battered child syndrome, Adolescence, Child health (Public health), Public health
\end{abstract}

Resumo A história mostra que, desde os tempos primitivos até o momento presente, a violência contra a criança se apresenta como um fenômeno social e cultural de grande relevância. Em diferentes sociedades as formas, as mais cruéis e as mais sutis, se diferenciam. No Brasil podemos distinguir uma violência estrutural, cujas expressões mais fortes são o trabalho infantil, a existência de crianças vivendo nas ruas e em instituições fechadas; uma violência social, cujas mais vivas expressões se configuram na violência doméstica; uma violência delinquencial, na qual as crianças são vítimas e atores. O Estatuto da Criança e do Adolescente oferece importante instrumento para que a sociedade e o estado possam, reconhecendo o protagonismo desses sujeitos, buscar superar as formas de violência que prejudicam o seu crescimento e desenvolvimento e, portanto, o desenvolvimento social.

Palavras-chave Violência, Criança maltratada, Adolescência, Saúde infantil (Saúde pública), Saúde Pública 
"Mi madre dice que no debe mimarse a los niños y me pega todas las mañanas; cuando no tiene tiempo por la mañana, lo hace al mediodia raras veces mas tarde de las cuatro. Mi madre aparece con frecuencia para agararme por las orejas y darme pescozones. Es por mi bien, de modo que cuantos más cabellos me arranca, cuanto más me abofetea, mas me convenzo de que es una buena madre y de que yo soy un hijo ingrato... Mi padre necesita descargar su pena sobre alguién y conmigo desahoga su pesadumbre, su cólera ..."

(Valles; 1985: 37).1

\section{A perenidade histórica da violência contra crianças e adolescentes}

Para iniciarmos uma reflexão sobre o tema, tomaremos aqui a definição construída por várias autoras brasileiras como Guerra, ${ }^{2}$ Assis, ${ }^{3}$ Deslandes, ${ }^{4}$ segundo as quais, a violência contra a criança e o adolescente é todo ato ou omissão cometidos por pais, parentes, outras pessoas e instituições, capazes de causar dano físico, sexual e/ou psicológico à vítima. Implica, de um lado, numa transgressão no poder/dever de proteção do adulto e da sociedade em geral; e de outro, numa coisificação da infância. Isto é, numa negação do direito que crianças e adolescentes têm de serem tratados como sujeitos e pessoas em condições especiais de crescimento e desenvolvimento.

A capacidade de gerar uma definição como esta é algo próprio à sociedade moderna, onde crianças e adolescentes se tornam sujeitos de direito, e portanto, reconhecidos como portadores de cidadania. Mas para a consciência moral da humanidade chegar ao ponto dessa afirmação, foi necessário que o movimento social pela cidadania, consagrado na Revolução Francesa, em 1789, contaminasse, pelas reivindicações ativas dos sujeitos coletivos, grupos sociais específicos com a grande corrente social do feminismo e por último, o movimento que teve como objetivo a cidadania da infância e da adolescência.

A violência contra esses grupos etários, conforme mostra Assis, ${ }^{3}$ acompanha a trajetória humana desde os acontecimentos mais primitivos de que se têm registro. E são também inumeráveis as modalidades pelas quais se expressa, dentro das diferentes culturas. Por exemplo, a eliminação de crianças e adolescentes é dos temas mais citados na história, abrangendo o infanticídio (crianças pequenas mortas pelos pais) e os homicídios. Conforme assinala Veyne, 5 a prática do infanticídio era aceita pelas sociedades antigas, sendo facultado aos pais, acolher ou renegar o filho recém-nascido. A própria Bíblia apresenta passagens em que, nos momentos de escassez de alimentação, o povo hebreu comia as crianças mais novas: "Dá cá o teu filho para que hoje o comamos e amanhã comeremos o meu filho. Coze- mos pois, o meu filho, e o comemos" (Bíblia. A.T. II Reis, 6: 26-29). 6

Embora sempre tenha persistido nas sociedades esse tipo de relação, levando De Mause ${ }^{7}$ a afirmar que a história da humanidade se fundou numa política de violência contra as crianças, esse comportamento paulatinamente passou a suscitar sanções da sociedade. Assis ${ }^{3}$ assinala que nos anos de 315-329 d.C., na Itália criou-se uma lei que propunha sujeitar as mãos dos pais, para afastá-los do infanticídio. A mesma autora cita que no ano 830 d.C., a mulher que matasse um recém-nascido ou tentasse abortar deveria ser excomungada, cabendo aos sacerdotes diminuir-lhe a pena e/ou dar-lhe uma penitência a ser cumprida. Na Inglaterra, no século XII, criou-se uma lei que tratava a morte de criança por nutrizes ou professores como homicídio de adulto.

A violência contra criança e adolescente, no transcorrer da civilização, além do caráter arbitrário dos pais de decidirem sobre sua vida, sempre esteve muito vinculada ao processo educativo. Ela tem sido considerada, em todos os tempos, como um instrumento de socialização e portanto, como resposta automática a desobediências e rebeldias. Uma lei hebraica do período 1250-1225 a.C. dizia que, caso os filhos não dessem ouvidos aos conselhos paternos, cabia aos anciãos, puni-los, expondo-os a serem apedrejados ou mortos. ${ }^{8}$ Os primeiros anos da era cristã suavizaram o rigor do Antigo Testamento, sem contudo aboli-lo, como o mostra Mc Laughin (1982: 121) $9 "$ "... pegar com vara de vime, suave e flexível ou então puxar pelos cabelos. Às crianças nunca se deve castigar com pontapés, nem com punho ou palma da mão aberta, nem de nenhuma outra forma". A violência maior, porém, a sociedade sempre reservou para as crianças abandonadas por seus pais. Badinter (1985: 58) ${ }^{10}$ menciona a descrição que faz Chamousett, em 1756, de 12 mil crianças abandonadas em Paris: "... morrem como moscas, sem nenhum lucro para o Estado. Pior ainda, representam um ônus para a nação, obrigada a mantê-las até que morram". Idealizando uma função militar para essas crianças, Chamousett, citado por Badinter, (1985:58) 10 diz que ... "filhos de pais sem apoio algum, além do que um sábio governo lhe proporciona, elas não têm a que se apegar e nada a 
perder". Em "Os Miseráveis", Victor Hugo11 diz que se notava no Boulevard do Templo e vizinhanças do Chateau d'Eau, um rapazinho de onze a doze anos, que com o riso de sua idade nos lábios, possuía um coração completamente escuro e vazio. Todavia o rapazinho tinha pai e mãe. Mas o pai não queria saber dele e a mãe não lhe tinha amizade. Era uma dessas crianças dignas de lástima, entre todas as que têm pai e mãe e são órfãs. Em parte alguma o rapazinho se sentia tão bem como na rua. Os pais arremessaramno à vida com um pontapé.

Embora muito se tenha caminhado na sociedade ocidental, do ponto de vista ideológico, há estudiosos que divergem da idéia de que sejamos hoje mais respeitosos com as crianças do que nos séculos passados. Em seu belo e extenso trabalho, Guerra ${ }^{2}$ comenta que, se no transcurso da história, as sociedades praticavam o infanticídio, os espancamentos, e os incestos, se muitos estados, no passado, sacrificaram e mutilaram suas crianças para aliviar a culpa dos adultos; em nossa época, tão ciosa de sua própria racionalidade, continuamos matando e mutilando crianças e as submetendo à fome.

Ariès 12 recupera a compreensão do fenômeno da violência desde a época medieval, sustenta que a criança na sociedade tradicional era mais feliz, misturava-se a seu meio social e aos adultos; diluindo-se assim, contra ela, a pressão e a opressão da família. A invenção da condição especial de "criança" foi, segundo o autor, fator fundamental para seu confinamento e para a atribuição de castigos severos como meio de educação. E Guerra² comenta que os terapeutas familiares hoje descobriram que, no caso específico do espaço doméstico, a violência contra as crianças tem por objetivo manter as famílias unidas, enquanto um meio de solução dos problemas emocionais dessa pequena comunidade. Da mesma forma, continua a autora, essa violência tem sido um meio efetivo de manter a homeostase emocional coletiva.

De Mause, 7 ao contrário, mostra uma certa suavização nas relações pais e filhos, passando os pais, de maltratantes a pais que se sacrificam pelos filhos. Porém, quando se refere à sociedade em geral, comenta que a história da humanidade se fundou numa prática de violência contra as crianças.

$\mathrm{Na}$ sociedade oriental, algumas tradições perpetuam a maldição desde os mais escuros e fundos tempos, atuando a serviço de uma certa "naturalização" do infanticídio. A recente reunião mundial de mulheres em Pequim trouxe a tona, através dos meios de comunicação de massa, um costume aberrante que se perpetua. Na Coréia do Sul, na China, na Índia, no Paquistão e em outros países asiáticos, milhões de meninas são mortas ao nascer. Essa lei inexorável, porque fundamentada na tradição, atinge os lares e tem sua continuidade no preço vil pago à mão-de-obra feminina, um dos trunfos da modernização e da concorrência das indústrias de exportação nesses países.

Concluindo, somos inclinados a concordar que o tema da violência contra a infância e a adolescência é uma forma secular de relacionamento das sociedades, variando em expressões e explicações. A sua superação é uma condição que se constrói ao mesmo tempo que a "pacificação da sociedade" e seu grau de civilização, porém necessita ser desnaturalizada e retirada do âmbito que a legitima, o processo pedagógico. O respeito a esses sujeitos sociais hoje é fundamental para que a sociedade adulta, em todas as instâncias e instituições, amadureça seu código de direitos humanos e direitos sociais. 13

\section{Formas e expressões de violência. $O$ caso do Brasil}

Embora a violência seja um fenômeno de difícil apreensão pelo grau de subjetividade, polissemia, polêmica e controvérsia que contém, podemos analisá-lo em suas formas e expressões. É nesse sentido que o tomaremos aqui, buscando contextualizar mais amplamente o que denominamos violência estrutural, delinqüência e violência intra-familiar, aprofundando com informações sobre a população de 60 milhões de crianças e adolescentes de 0 a 17 anos existente no país no ano 2000.14 Desta forma, não pretendemos nem ser exaustivos nem dar conta da questão.

\section{Violência estrutural}

Entendemos por violência estrutural, aquela que incide sobre a condição de vida das crianças e adolescentes, a partir de decisões histórico-econômicas e sociais, tornando vulnerável o seu crescimento e desenvolvimento. Por ter um caráter de perenidade e se apresentar sem a intervenção imediata dos indivíduos, essa forma de violência aparece "naturalizada" como se não houvesse nela a ação de sujeitos políticos. Portanto é necessário desvendá-la e suas formas de reprodução através de instrumentos institucionais, relacionais e culturais.

A maior expressão dessa violência pode ser representada pelas 20 milhões de crianças e adolescentes brasileiras de 0 a 17 anos $(34,8 \%$ do total da faixa etária), que ainda no ano 2000 se encontram em situação de pobreza, vivendo em famílias com 
renda média mensal familiar de até $1 / 2$ salário mínimo per capita. Em regiões mais pobres do país, como o Nordeste, este percentual chega a $58,8 \%$, mostrando a gravidade e persistência da enorme desigualdade social, refletida nas precárias condições de vida dessas crianças e adolescentes. 14

Agravando essa situação, constata-se a precária condição educacional das crianças e adolescentes brasileiros. Apesar do decréscimo do analfabetismo no país, em 1997 a média de anos de estudo das crianças de 7 a 14 anos de idade foi de apenas 3,4; $8,7 \%$ dos adolescentes entre 10 e 14 anos e 5,4\% entre 15 e 17 anos foram considerados analfabetos; o analfabetismo funcional (menos de 4 anos de estudo) de adolescentes brasileiros entre 15 e 17 anos foi de $20,2 \%$, enquanto entre os nordestinos observouse $39,2 \%$ de analfabetos funcionais; a defasagem idade/série é muito elevada, sendo o Nordeste mais uma vez a região campeã, com $89,8 \%$ dos adolescentes de 14 anos com atraso escolar. Os dados levantados pelo Instituto Brasileiro de Geografia e Estatística (IBGE; 1997: 47)14 o levam a concluir que "... a desigualdade no acesso à escola são marcadas pela condição econômica das famílias [...] confirmando a teoria de que a renda familiar é um determinante da freqüência escolar".

Outro elemento que contribui para a naturalização da violência que atinge crianças e adolescentes são os programas dos meios de comunicação, recente alvo de preocupação das instituições de vários países do mundo, pela forma como esse instrumento de alto impacto na cultura moderna tende a banalizar as agressões e as mortes. 15 Pesquisa realizada no Rio de Janeiro, em 1998, com 1.220 jovens de todos os estratos sociais mostra como a violência na mídia é vista pelos jovens. As cenas de agressão física exibidas pela tevê são consideradas uma reprodução da realidade, para cerca de metade dos jovens cariocas. Revelam também que a televisão discrimina os jovens das camadas populares, sobretudo os moradores de favelas e periferias, associando-os à criminalidade e reforçando o estereótipo do jovem negro e favelado. Os jovens informam ainda que a propaganda os influencia ao consumo e que alguns se envolvem com delitos para terem acesso a bens de consumo aos quais, de forma geral, não teriam acesso pela via legal. 16

Situações como essas, geradas no âmbito da cultura, só incomodam quando as próprias vítimas, através de algum mecanismo de resistência (inclusive a delinqüência) ou algum movimento de consciência social, as presentificam em forma de denúncia.

Em um de seus muitos trabalhos sobre a infância pobre no Brasil, Rizzini, ${ }^{17}$ comenta que talvez o único efeito positivo das chacinas envolvendo crianças e adolescentes nos últimos anos, em todo o país, seja trazer a tona um problema que vem de longa data sem que a sociedade brasileira o tenha enfrentado. A mão que executa crianças quase sempre está ligada a opções econômicas e políticas que conduziram crescentes parcelas da infância à condição de marginalidade. Buscando datar sua fala, Rizzini17 revela que a trajetória da não-cidadania das crianças brasileiras tem origem no período colonial. Porém no momento de instauração do regime republicano, o país viveu a oportunidade de mudar os rumos da história, quando se debatia a importância de investir na infância. Ao invés de optar por políticas sociais capazes de proporcionar condições eqüitativas de desenvolvimento, o país criou um complexo sistema de tutela do Estado sobre a infância pobre. Estabeleceu e institucionalizou, assim, a divisão entre infâncias privilegiadas sob o manto protetor das famílias e infâncias marginalizadas, cujo destino passou a ser decidido nos asilos, nas casas de detenção, nos juizados de menores ou no interior das próprias famílias como menores trabalhadores. Tal situação perdura há 100 anos, sendo sempre diagnosticada, a posteriori, como "problema grave", "prioridade" de governos, "escândalo" para a diplomacia internacional, sem que, na verdade, redunde em objeto de convicção ou determinação política.

Em suas expressões, a violência estrutural tem várias formas-limite de manifestação. Três maiores expressões de vulnerabilidade são comentadas a seguir: os chamados "meninos e meninas de rua"; os "meninos e meninas trabalhadores" e as "crianças e adolescentes institucionalizados".

Em relação aos meninos e meninas de rua, muitos estudos têm sido feitos no país e nós mesmos buscamos, através da literatura existente e de trabalho de campo por amostragem em todas as regiões do país, traçar o seu perfil.18 Tanto a bibliografia exaustivamente analisada, como nossa experiência de campo revelaram que a primeira causa de ida para a rua, por parte das crianças e adolescentes, é a miséria e absoluta falta de condições familiares para sua subsistência; e a segunda, que constitui o tópico seguinte de nossa reflexão, são os conflitos familiares. Nas ruas, eles convivem com ameaças a sua vida, indução ao crime, maus tratos praticados por policiais ou por outros, sendo explorados por comerciantes, seguranças, além de serem estigmatizados como "futuros bandidos".

É bem verdade que o fenômeno meninos de rua não é nem recente e nem privilégio do Brasil. Praticamente todos os países da América Latina apresen- 
tam essa forma de violência estrutural;19 e também nos Estados Unidos este fenômeno evidencia-se nos momentos de crise econômica.

A exploração do trabalho infanto-juvenil constitui-se numa segunda expressão muito forte da violência estrutural. Segundo dados do IBGE, durante a década de 80 a taxa de atividade média de crianças na faixa dos 10 a 14 anos era de $18 \%$, no auge da crise econômica do ano de 1992 passou para 22,4\%. A Pesquisa Nacional por Domicílios do IBGE de 1997 felizmente constata uma queda nos percentuais na década de 80 e início dos anos 90 . Hoje são 2,9 milhões de pessoas da faixa etária de 10 a 14 anos que estão trabalhando (16,9\%). Entre os jovens de 15 a 17 anos constatou-se um decréscimo de $54,3 \%$ em 1992 para 45,9\% em 1997, totalizando 4,8 milhões de jovens trabalhadores. As diferenças regionais novamente se destacam em 1997, quando ainda $24 \%$ das crianças nordestinas na faixa dos 10 aos 14 anos contra $13,2 \%$ das sulistas. As crianças e adolescentes representam ainda $10,1 \%$ da força de trabalho existente no país, no final deste século. 20 Ressalta-se que essas estatísticas não contemplam o trabalho de crianças com menos de 10 anos, comum tanto em área rural (agricultura) como urbana (mercado informal). Estimativas para o ano de 1995 informam que existiam no país 522 mil crianças trabalhadoras com menos de 10 anos, representando 3,25\% das crianças naquela faixa etária. 21

Mateos 22 fez uma verdadeira radiografia desta situação no país, mostrando que essa forma de exploração existe em setores que empregam grande quantidade de mão-de-obra em relação ao capital investido. Nisso se incluiam indústrias modernas como as siderúrgicas e as exportadoras de calçados e suco de laranja, além do Projeto Proalcool como um todo, indústrias metalúrgicas, naval e de eletrodomésticos. A participação dessas empresas se dava de forma indireta, através dos processos de terceirização e flexibilização.

Nessas novas formas de organização de trabalho, crianças e adolescentes entram em grupos formados por trabalhadores que se reúnem para prestar serviços às grandes empresas, quase sempre ganhando muito pouco, sem direitos sociais e com intensificação das jornadas. Mateos 22 mencionava jornadas de 12 horas para crianças em carvoarias, 11 horas na colheita de laranja e 12 horas nos cortes de cana. Respondendo à pergunta "quem garante o faturamento e a sobrevivência de empresas exploradoras de crianças?" a autora mostrava que, em última instância, a Petrobrás, a Mercedes Benz, a Volkswagen, a Bombril, a GM, a Ford, a Fiat, a Cofap, a Cosipa, eram algumas das compradoras de insumos produzi- dos por estas crianças ou de produtos fabricados a partir delas. Dados do IBGE mostram que é elevada a jornada de trabalho, a ponto de apenas $1 / 4$ dos adolescentes de 15 a 17 anos conseguirem conciliar estudo com trabalho. 14

Mas esse também não é um problema exclusivamente brasileiro. Mateos 22 assinala em seu trabalho situações muito graves de trabalho infantil em Portugal, na Espanha e na Alemanha. Certamente seu estudo não é exaustivo. Um levantamento mais completo mostraria uma abrangência muito maior dessa forma de violência. A exploração do trabalho de crianças e adolescentes vem acompanhando o processo de globalização.

O caso do trabalho infantil no Brasil vem sendo fortemente acompanhado e desestimulado pelas Organizações Não-Governamentais (ONGs) de defesa de direitos e pela Fundo das Nações Unidas para a Infância (UNICEF). Igualmente o próprio governo, através do Ministério da Justiça, está monitorando o problema e criando políticas compensatórias que incentivem os pais a colocarem seus filhos e os manterem na escola. Esse investimento coletivo que se intensificou nos últimos três anos explica, em parte, o relativo sucesso mostrado pela diminuição das taxas de emprego infantil. O monitoramento do problema, porém, não consegue competir integralmente com as situações de miséria relativa e absoluta que permanecem no país e são as verdadeiras produtoras do status de menor trabalhador.

Uma terceira forma de expressão da violência estrutural é a institucionalização de crianças e adolescentes, seja como meio de se contrapor ao abandono, seja por motivos considerados ressocializadores. Toda a história revela não só a ineficácia, mas a total incompetência dessas instituições, asilos, reformatórios, serviços de assistência e de "bem estar" entre os quais o Serviço de Assistência ao Menor (SAM), a Fundação Nacional do Bem-Estar do Menor (FUNABEM) e as Fundações Estaduais do BemEstar do Menor (FEBEMs) por exemplo, para prover o crescimento e o desenvolvimento desses seres discriminados. Uma pesquisa específica de Altoé23 descreve o cotidiano de crianças e adolescentes institucionalizados em uma determinada fundação filantrópica do Rio de Janeiro, que atende a 2.000 desses estudantes pobres. A autora detalha os meandros da violência e da inadequação motivadas por transferência múltipla de ambiente de vida; rodízio de funcionários; atendimento impessoal e despersonalizante; impossibilidade de construir laços objetivos significativos; hipoestimulação do desenvolvimento motor; fechamento para o mundo exterior, monotonia do cotidiano e pobreza das relações sociais. 
Nessas instituições, o sistema disciplinar rigoroso e punitivo castra qualquer expressão de liberdade e autonomia. O caráter do castigo imposto impossibilita a internalização da disciplina, de forma positiva, favorecendo o desenvolvimento de uma personalidade rígida, com baixa auto-estima e dependente. Altoé 23 afirma ainda que o sofrimento é fabricado pelo sistema institucional que, na tentativa de resguardar, proteger e educar, torna a vida de milhares de crianças brasileiras infâncias desperdiçadas, infâncias perdidas, expropriadas das possibilidades de futuro.

O estudo de Oliveira e Assis 24 ressalta a perpetuação do descaso para com os jovens infratores em unidades de internação do Rio de Janeiro. Analisando o ano de 1994, constata que o governo estadual não encara como prioridade o atendimento aos jovens nas instituições de custódia: " ... algumas instituições se apresentam deterioradas quanto a estrutura física e escassez de material; não se implementou a escola formal nem iniciação profissional efetiva. Continuam superlotadas e com freqüentes rebeliões, inapropriadas para a socialização dos jovens, desumanas e descumprindo o Estatuto da Criança e do Adolescente" (Oliveira e Assis; 1999: 822).24

A vivência dos jovens nas instituições cariocas configura-se como uma etapa de aprendizado do crime. O sentimento de impotência vivido pelos profissionais destas instituições, a histórica precariedade de recursos humanos e materiais e a prática institucional impregnada pelo desrespeito, também comprovam a insanidade do sistema e das políticas públicas. 24

Outro estudo tomando como base o ano de 1997, mostra que houve pouca melhora nessas instituições. 25 Os programas educativos e profissionalizantes são insuficientes, inadequados e ineficientes. A maioria das instituições não organiza cursos formais cujos objetivos despertem o interesse dos jovens. Os chamados "profissionalizantes" são vistos pelos adolescentes como sem utilidade para suas vidas, ou requerem um nível de escolaridade não alcançado pela maioria. A autora comenta que o processo pedagógico segue uma lógica despersonalizante e padronizada, não dando conta das individualidades e das necessidades dos infratores. A violência como forma de relação no interior da instituição é reiteradamente relatada por eles, tanto no relacionamento entre os jovens, como deles com os agentes de segurança.

A situação das meninas infratoras internas é também muito preocupante, pois, além de não haver a escolarização formal, os cursos oferecidos são voltados para o universo doméstico (corte e costura, bor- dado, culinária) ou de embelezamento pessoal, contribuindo para desmotivá-las quanto à inclusão social e a afastá-las ainda mais do competitivo mercado de trabalho. 26 Somam-se a isso o forte controle da sexualidade feminina e a intensa presença da intervenção psiquiátrica e da medicalização, substituindo um projeto pedagógico fundado na valorização da pessoa. Em contrapartida são freqüentes as manifestações de auto-agressividade das meninas internadas que chegam a se impingir mutilações e suicídio.

Por outro lado, essas pesquisas mostram que apenas um percentual pequeno das crianças e adolescentes institucionalizadas não têm família. Isso vem de encontro a nossa primeira afirmação sobre a violência estrutural de que, esse abandono vem associado à miséria, solo fértil para a eclosão de outras crueldades.

\section{Violência intra-familiar}

A violência intra-familiar é aquela exercida contra a criança e o adolescente na esfera privada. Geralmente se usa dividir em quatro tipos suas expressões mais visíveis.

A violência física que é o uso da força física contra a criança e o adolescente, causando-lhes desde uma leve dor, passando por danos e ferimentos de média gravidade até a tentativa ou execução do homicídio. Em geral, as justificativas para tais ações vão desde a preocupação com a segurança, a educação, até a hostilidade intensa. O lar aparece como o local privilegiado para tal prática, embora as crianças que vivem nas ruas ou as institucionalizadas sejam também vítimas freqüentes. Dados do IBGE27 apontam que, em 1988, 200.000 crianças e adolescentes declararam ter sofrido agressão física, de um total de 1 milhão de queixosos, ou seja, há uma estimativa de $20 \%$ dessa população como vítima. Desse total, em $80 \%$ dos casos, os agressores eram os próprios pais, parentes e conhecidos.

Em 1992, Assis 28 concluiu uma pesquisa no município de Duque de Caxias, Rio de Janeiro, com 1.328 adolescentes, de escolas públicas e particulares sobre violência física. Seus dados revelam que $75 \%$ dos entrevistados referiram os irmãos como autores de atos violentos; $40 \%$ o pai e $45 \%$ a mãe. A ocorrência de agressão severa (uso de armas ou outros instrumentos) foi referida por $40 \%$ dos adolescentes. A partir dos indicadores disponíveis, a autora estimou que 10.955 dos estudantes do municípios, em 1991, conviviam quotidianamente com a violência familiar, sendo que 2.665 deles suportavam e sofriam formas mais graves de agressão. Moraes, 29 
estudando 212 casos de maus-tratos atendidos desde 1996 no Ambulatório de Família da Universidade Federal do Rio de Janeiro, encontrou 35,1\% de casos confirmados dessa forma de violência. A literatura internacional mostra que $70 \%$ dos atos de violência física, em geral, são cometidos pelos pais, e as faixas de idade mais vulneráveis são as de 7 a 13 anos. ${ }^{2}$ É importante mencionar que se trata de um fenômeno que se revela em todas as classes sociais.

As conseqüências mais freqüentes de violência física são lesões abdominais, fraturas de membros, mutilações, traumatismos cranianos, queimaduras, lesões oculares e auditivas, muitas delas levando a invalidez permanente, ou temporária, ou até à morte.

Muitos autores, dentre eles Guerra ${ }^{2}$ associam (obviamente, de forma não-linear) punição física com delinqüência, por causa dos sentimentos ambíguos, confusos ou vingativos que ela gera, como angústia, raiva, ansiedade, medo, terror, ódio e hostilidade. Dentre as expressões dessa "revanche" provocada pela violência física, muitos estudiosos colocam o parricídio, o matricídio ou o fratricídio, fechando o ciclo do abuso infantil.

A violência sexual que se configura como todo ato ou jogo sexual, relação hetero ou homossexual entre um adulto (ou mais) em uma criança ou adolescente, tendo por finalidade estimulá-los sexualmente e obter estímulo para si ou outrem. ${ }^{2-4}$ Nos estudos sobre tal fenômeno, todos os autores indicam a existência de abuso sexual no âmbito familiar. 30 Os principais agressores são o pai, o padrasto, ou ainda, pessoas conhecidas e do relacionamento familiar com a vítima. Essa forma de abuso costuma ter como conseqüência a saída do lar, principalmente por parte das meninas. Na rua, os agressores costumam ser policiais e companheiros, quando muitos estupros são relatados pelas adolescentes. Para muitas delas, tais violências resultam em gravidez precoce e indesejada, assim como em casos de aborto.

A quantificação da violência sexual é muito difícil porque, envolvido em tabus culturais, relações de poder nos lares e discriminação das vítimas como culpadas, esse fenômeno aparece substimado nas estatísticas do sistema de saúde e das secretarias de polícia. Porém alguns exemplos localizados podem ilustrar a sua ocorrência.

Dados do Centro Brasileiro da Criança e do Adolescente de Recife (CBCA) ${ }^{31}$ registram 3.667 crimes, de 1987 a 1989, sendo que $37 \%$ estavam relacionados a posse sexual mediante fraude e sedução; e $13 \%$ eram casos de estupro. Em São Paulo, Saffioti32 estudou 346 crimes contra crianças e adolescentes em 1991 e encontrou 19,9\% de estupros e $17,5 \%$ de atentado ao pudor. $\mathrm{Na}$ pesquisa de
Deslandes ${ }^{4}$ sobre as notificações de violência contra o mesmo grupo, nos Centros Regionais de Atenção aos Maus-Tratos na Infância (CRAMIS), a autora observou que $7 \%$ de todas elas se referiam a abuso sexual. Moraes, ${ }^{29}$ investigando uma unidade que funciona dentro de um hospital universitário, constatou maior percentual de encaminhamentos por abuso sexual: $31,6 \%$ dos casos suspeitos e $15,3 \%$ dos confirmados.

A violência psicológica, também denominada tortura psicológica, que ocorre quando os adultos siste-maticamente depreciam as crianças, bloqueiam seus esforços de auto-estima e realização, ou as ameaçam de abandono e crueldade. Trata-se de um tipo de relação muito pouco estudado entre nós, mas que tem um efeito muito perverso no desenvolvimento infanto-juvenil. Em seu trabalho recente, Guerra, 2 recuperando as idéias sobre a natureza infantil na Europa do século XVII e XVIII, mostra que Locke, por exemplo, a considerava como uma natureza menor, a ser moldada pela compreensão do adulto como poderoso e moralmente certo. Dessa forma, segundo seu ponto de vista, era importante se exercer a violência física contra a teimosia, junto com a inculcação do sentimento de culpa e de vergonha. Nos Estados Unidos a violência psicológica é hoje bastante notificada, comparecendo com cerca de $8 \%$ de todas as denúncias de violência.

Os estudos de Deslandes 4 nos Centros Regionais de Atenção aos Maus-Tratos na Infância (CRAMIs) de São Paulo classificam esse tipo de violência como tendo uma notificação relativa, ainda pouco presente, com 16,4\% do total das agressões. Moraes 29 identificou $20,7 \%$ de casos confirmados de maustratos psicológicos entre as crianças e adolescentes atendidas em ambulatório especializado para vítimas de violência. Trata-se aqui, também, de um tabu, pois a criança e o adolescente continuam, apesar do Estatuto da Criança e do Adolescente (ECA), a serem considerados posse exclusiva dos pais, o que lhes daria o direito de tratá-las como bem entendessem. Desta forma o abuso psicológico freqüentemente é tido como forma de educar com rigor.

A última classificação que é importante mencionar são as negligências. Elas representam uma omissão em relação às obrigações da família e da sociedade de proverem as necessidades físicas e emocionais de uma criança. Expressam-se na falta de alimentos, de vestimenta, de cuidados escolares e com a saúde, quando as falhas não são o resultado de circunstâncias fora do controle e alcance dos responsáveis pelos adolescentes e crianças. Trata-se de um tipo de ação difícil de ser quantificado e qualificado, sobretudo quando as famílias estão em situação de 
miséria. Nos Estados Unidos, hoje se notificam intensamente as negligências, constituindo-se em $45 \%$ das agressões contra a infância, nas estatísticas oficiais.

Em pesquisas realizadas nos CRAMIs, Deslandes 4 encontrou um percentual de notificação de $23,5 \%$ no total das violências registradas, só abaixo das agressões físicas. A autora observa que a relevância do percentual para a negligência, ao que tudo indica, está associada a situações limítrofes entre pobreza e maus-tratos. Ou seja, uma vez que a negligência se define pela omissão no trato dos cuidados e necessidades das crianças, a reconhecida ausência de condições econômicas dessas famílias muitas vezes dificulta o julgamento mais preciso entre prática abusiva e impossibilidade de prover atenção. No entanto, a escassez de dados sobre as classes médias e altas não pode esconder a hipótese de que, possivelmente nesses grupos sociais, a negligência e o abuso psicológico (além das agressões físicas) constituam problema relevante. Essa hipótese está associada ao próprio modo de vida desses estratos, onde a concorrência e outros estímulos tendem, de um lado, à ausência real e moral dos pais de seus lares e, de outro à pressão sobre crianças e adolescentes para se destacarem social, econômica e intelectualmente, em função do sucesso futuro no mercado de trabalho.

As análises sobre o fenômeno da violência intrafamiliar nos levam a concluir que os lares não são tão sagrados quanto parecem, embora várias experiências mostrem que são espaços passíveis de intervenção para mudanças. Sobretudo porque a violência contra a infância e a adolescência é reconhecida como componente importante da violência social e como elemento propulsor e reprodutor de suas expressões, o campo das intervenções tem que contemplar o âmbito cultural, da prevenção e também, por vezes, a repressão e o castigo de pais que mutilam ou até matam seus filhos.

\section{Violência infanto-juvenil}

Em geral a imprensa nacional e mundial se esmera em mostrar o outro lado da violência, ou seja, o da delinqüência infanto-juvenil. Esse problema não é apenas nacional. O estudo de Assis e Constantino 26 mostra que no Rio de Janeiro, no ano de 1994, havia 134 jovens de 12 a 7 anos para cada cem mil habitantes da mesma faixa etária, enquanto na cidade de Nova York encontrava-se uma relação de 1.045 jovens de 10 a 17 anos por cada cem mil jovens daquela cidade.

Em todo o país, no ano de 1997, havia 20.352 adolescentes entre 12 e 20 anos cumprindo medidas sócio-educativas (internamento, semi-internamento, escolas especiais, serviço à comunidade), em sua maioria do sexo masculino (há uma relação de 12 infratores masculinos para cada feminino). ${ }^{33}$ Segundo Volpi, 34 havia no Brasil, nos anos de 1995 e 1996, 4.245 adolescentes privados de liberdade. Observando as informações sobre renda familiar, $25 \%$ deles provêm de famílias que recebem menos de um salário mínimo e 34,2\% entre 1 e 2 salários mínimos, comprovando a origem social mais pobre dos indivíduos internos em instituições.

Assis, ${ }^{3}$ em vários de seus trabalhos mostra que esse assunto já preocupava a sociedade greco-romana. Rapazes ricos tinham o hábito de percorrer as ruas aos bandos, à noite, espancando e maltratando pessoas e destruindo lojas. Veyne 5 comenta que a punição primeira era a admoestação pelo governo, e os casos de reincidência eram tratados com açoites. Em todas as sociedades, atuais e mais antigas, os bandos de adolescentes molestando adultos e propriedades são costumeiros e geralmente desculpados como eventos próprios à rebeldia da idade. Também Burke 35 menciona o papel das gangues de rapazes na sua análise histórica, que vai desde 1590, início da Idade Moderna, até nossos dias.

Numa sociedade com tantas desigualdades como a brasileira, esse fato necessita ser analisado com maior cuidado, porque aparece quase sempre associado à questão de classe, e como problema dos pobres, crianças de rua ou institucionalizadas. É por isso que propomos tratá-lo articulado à violência estrutural, inclusive porque costuma ser usado, por grupos voltados para a "limpeza social", como álibi para extermínios, execuções e homicídios. Por exemplo, um estudo do Centro de Articulação de Populações Marginalizadas (CEAP), 36 informa as ocupações dos jovens vítimas de homicídios em 1992 e 1993 no Rio de Janeiro como sendo estudantes, aviões/traficantes, e assaltantes, mas $60 \%$ dos mortos não tinham nenhuma vinculação com a criminalidade, ou seja, eram simplesmente crianças e adolescentes pobres.

Nesses casos junta-se o preconceito com a situação de precariedade de qualquer projeto de vida. Nos grandes centros urbanos as alternativas são a indústria da droga, o subemprego, ou empregos considerados desqualificados. Tomando como exemplo o Rio de Janeiro, para onde temos informações, uma pesquisa dem1996, da $2^{\text {a }}$ Vara da Infância e Adolescência, vinculada à Secretaria de Justiça do Estado, oferece alguns dados, segundo os quais $49 \%$ dos infratores moram em favelas; o número de infratores tende a crescer; e a maioria dos delitos ocorre na 
Zona Sul, a Zona considerada mais rica da cidade.

A adesão de crianças e adolescentes ao tráfico de drogas não deve causar espanto. O tráfico hoje é considerado uma alternativa à exclusão que os jovens pobres e de pouca instrução sofrem no mercado de trabalho formal. Por outro lado, estudos da $2^{\text {a }}$ Vara da Infância e Adolescência do Rio de Janeiro 37 para o ano de 1999 provam que essas crianças e adolescentes não são tão perigosos como se apregoa. Suas infrações se dirigem contra o patrimônio $(32,5 \%)$, estão vinculadas a entorpecentes $(33,7 \%)$, contra a pessoa $(12,1 \%)$, contravenções $(6,7 \%)$, contra os costumes $(1,4 \%)$; e outros crimes $(13,6 \%)$.

A delinqüência infanto-juvenil é proporcionalmente muito menor do que a reação da sociedade contra ela. Segundo o Juiz da $2^{a}$ Vara, de janeiro a outubro de 1995, mais de 1.000 menores morreram de forma violenta no Rio de Janeiro, sendo que $60 \%$ assassinados, e $40 \%$ em óbitos no trânsito e nos chamados "autos de resistência", ou seja, em confronto com a polícia. O mesmo juiz denuncia o aumento de ações de extermínio, cometidas por policiais militares e outras categorias de pessoas.

Essa situação de delinqüência, que sem dúvida tem causas sociais, não é problema só do Brasil. Nos Estados Unidos, um relatório do Fundo de Defesa da Criança publicado em junho 1995, aponta que 255 crianças/adolescentes são presas por dia por causa de drogas e 318 por terem abusado do consumo de álcool. No total são 5.504 menores de 18 anos presos diariamente, 327 deles por terem cometido crimes violentos. 38 A situação americana, no entanto, não nos consola, porque se trata de um país onde a violência é tratada como questão importante para política social e onde a notificação é muito séria. Ou seja, se lá a cultura da violência está muito arraigada, aqui necessitamos de muito esforço para tomá-la como questão pública e impedi-la de se tornar um traço forte de nossa cultura.

\section{Violência contra crianças e adolescentes e a saúde}

As mais evidentes manifestações da violência estrutural sobre a saúde infantil expressam-se nas taxas de mortalidade infantil e de crianças menores de cinco anos. Embora nas duas últimas décadas tenha havido significativa redução da mortalidade, ainda hoje o Brasil detém uma taxa média dentre as mais elevadas na América Latina. Enquanto no ano de 1998 o Brasil apresenta uma taxa de 42 óbitos em menores de cinco anos e de 36 entre os menores de um ano de idade, a Argentina e os Estados Unidos (EUA) ostentam taxas bem menores: 22 e 19 no país latino americano e 8 e 7, respectivamente, no país norte americano. ${ }^{21}$ As diferenças regionais atingem distintamente a saúde infantil: as crianças nordestinas têm muito mais probabilidade de morrer do que as do restante do país (a taxa de mortalidade infantil nessa região chega a 59, por 1.000 nascidos vivos).

Outro exemplo das conseqüências da violência estrutural se dá no crescente problema da gravidez na adolescência e de sua vinculação com situações de pobreza. Dados do IBGE mostram que as adolescentes pertencentes aos estratos de menor renda são as que têm mais filhos e em idades mais precoces. Em 1997, 9\% das adolescentes brasileiras de 15 a 17 anos com renda familiar per capita até $1 / 2$ salário mínimo tiveram filhos nascidos vivos. Dentre as adolescentes com renda superior a 2 salários mínimos, este percentual cai para $0,8 \% .14$

Manifestações diretas da violência contra crianças de baixa idade surgiram nos textos médicos desde o século XIX. Guerra² faz uma recompilação histórica de um trabalho de Tardieu em 1860, na França denominado Etude Médicien-légale sur les services et mauvais traitement exercés sur des énfants. Esse médico apresenta uma análise de 32 casos com 18 mortes, a metade de crianças com menos de cinco anos. Tardieu já então se refere à discordância entre as explicações dadas pelos agressores e as características das lesões. Os autores dos crimes eram pais, professores e autoridades.

A partir de Tardieu, porém, na França não se conhece nenhum movimento significativo de denúncia de violência contra a infância. É nos Estados Unidos, a partir da década de 60 que se retorna a questão como problema médico-social. Os pioneiros foram Kempe e Kempe 39 cujo trabalho foi registrado no livro Child abuse, narrando o estudo de 749 casos com 78 mortos, caracterizando o que a partir de então passou a se chamar Síndrome da Criança Espancada. Seguindo esses autores, sobretudo os pediatras passaram a tratar do tema, mostrando as seqüelas dos maus tratos (fraturas, queimaduras, sufocamentos, envenenamentos, dentre outros) e as discrepâncias entre as evidências radiológicas sobre as lesões e as explicações dos agressores. Embora esse movimento no interior da medicina tenha provocado muitas críticas pelos que o acusam de "medicalização da violência", ele teve e ainda tem uma enorme influência tanto na produção teórica, no desencadeamento de pesquisas, como nos movimentos de defesa dos direitos infanto-juvenis. A repulsa social à violência sexual, iniciada no campo médico, tomou corpo e consistência, também a partir dos EUA, como conseqüência do movimento feminista, na década de 70 .

No campo da saúde pública é na década de 80 
que a violência aparece como questão substantiva. Os movimentos de prevenção e de atenção especializada surgem em consequiência do reconhecimento da morbi-mortalidade por violência como um problema muito sério, tanto para a saúde nos seus aspectos sociais, como objeto de atenção primária, secundária e terciária. Também no Brasil, é nos anos 80 que começam a se esboçar diagnósticos e propostas, pari passu com o movimento social que desemboca na Constituição de 1988 e no Estatuto da Criança e do Adolescente (ECA). Desta forma, hoje já se têm dados de mortalidade e morbidade, ainda que não suficientes, capazes de dar suporte à políticas e estratégias de ação, como se verá a seguir.

Os estudos epidemiológicos revelam como principais resultantes da violência, as fraturas e queimaduras em crianças de baixa idade, e as lesões por agressões físicas e suicídios, esses últimos sobretudo na adolescência. Tais achados têm sido reiteradamente demonstrados na literatura. Deslandes, 40 investigando o atendimento de emergência prestado a 1.748 crianças e adolescentes em dois hospitais públicos do Rio de Janeiro, relata a elevada freqüência de "quedas" (39\%), principal causa de atendimento de crianças pequenas e as violências interpessoais (agressões, violência doméstica e "balas perdidas") mais comuns entre adolescentes. Informa ainda a presença significativa de violências auto-infligidas (suicídio e overdoses de drogas).

A visibilidade, a compreensão e a magnitude da morbidade ainda ficam muito prejudicadas por várias razões. As notificações de agravos por violência ainda não constituem uma cultura internalizada na sociedade brasileira, como mostram os estudos de Deslandes; 4 somente os de média e intensa gravidade chegam aos hospitais ou centros de saúde; e muitos dos eventos que aí chegam, não são diagnosticados como tal pelos profissionais de saúde, seja por falta de formação para esse diagnóstico, seja por falta de interesse de entrar em questões não biológicas. Em geral, a violência intra-familiar, particularmente, é tratada como problema do âmbito íntimo e privado das famílias.

Há hoje, no Brasil, atuando na área de saúde, na desnaturalização da cultura patriarcal e prevenção, algumas instituições, como os Centros Regionais de Atenção aos Maus Tratos na Infância (CRAMIs) de Campinas e outros municípios de São Paulo, Associação Brasileira de Proteção à Infância e a Adolescência (ABRAPIA) e Associação Brasileira de Crianças Abusadas e Negligenciadas, em Belo Horizonte, o Laboratório da Criança (LACRI) em São Paulo, e no momento a forte presença da Sociedade Brasileira de Pediatria (SBP) 41 que merecem desta- que. Há igualmente grupos hospitalares e ambulatoriais como o Instituto de Pediatria da Universidade Federal do Rio de Janeiro, estruturados para este tipo de atendimento. Mas seu âmbito de ação é ainda restrito e pouco visível.

A mortalidade por violência constitui-se atualmente na $2^{\mathrm{a}}$ causa de morte para a população em geral, a primeira para as crianças e adolescentes de 5 a 19 anos e a segunda entre crianças de 1 a 4 anos, perdendo, nessa última faixa etária, por pouco para as doenças do aparelho respiratório. Para se ter idéia de sua magnitude, em 1996, de todas as mortes de crianças entre 1 e 4 anos, 22,6\% se deveram as causas violentas; entre 5 e 9 anos, $48,2 \%$ foram por violência (na sua quase totalidade por acidentes de trânsito e homicídios); na faixa de 10 a 14 anos, foram $56,3 \%$; e no grupo de 15 a 19 anos, $72,2 \% .14$ Ou seja nosso contingente infanto-juvenil está morrendo mais por conflitos sociais que por doenças.

Essa situação é particularmente preocupante porque nos últimos 15 anos está havendo um deslocamento da incidência dos homicídios (dentre as causas externas de morte, a que mais cresce) para faixas de idade mais jovens.

Conforme mostra Souza42 em sua análise epidemiológica, houve um crescimento proporcional, na década de 80 , da ordem $79 \%$ nos óbitos por homicídios nos grupos de 10 a 14 anos e de 45,3\% nos de 15 e 19 anos. Essa intensificação das mortes por homicídios em faixa etárias mais jovens que aquelas onde são tradicionalmente mais freqüentes, deve-se, sobretudo, à vitimização dos componentes do sexo masculino, para os quais, a mortalidade na faixa de 10 a 14 anos cresceu $93,3 \%$ e na de 15 a 19 anos, aumentou $43 \%$. Também no sexo feminino, a faixa de 10 a 14 anos teve um salto expressivo de 43,9\%. Souza e Minayo43 chamam atenção para a faixa de 0 a 4 anos, na qual as proporções de mortes por causas externas, apesar de sua baixa freqüência, passam de $2,3 \%$ para $3,8 \%$ de 1980 a 1989 , significando um salto de $65,2 \%$. Ora, estudos qualitativos realizados por Mello Jorge 44 em São Paulo, sobre esse grupo de idade, revelam se tratar, quase todas, de mortes por crimes domésticos.

Esse tipo de mortalidade de crianças e jovens tem causado impacto na dinâmica do atendimento emergencial e é responsável por parte dos elevados custos da violência para a saúde. 45 


\section{Algumas considerações para a área de saúde}

A área da saúde tradicionalmente tem concentrado seus esforços em atender os efeitos da violência: a reparação dos traumas e lesões físicas nos serviços de emergência, na atenção especializada, nos processos de reabilitação, nos aspectos médico-legais e nos registros de informações. Ultimamente, ainda de forma localizada e como iniciativas voluntárias, ou seja, ainda não institucionalizadas, começa a haver uma abordagem mais integral, incluindo aspectos psico-sociais, tanto do impacto sobre as vítimas como nos fatores ambientais de caracterização dos agressores. 46

A Sociedade Brasileira de Pediatria junto com o Ministério da Justiça e a Fundação Oswaldo Cruz recém lançou um Guia sobre atenção aos maus-tratos para profissionais de saúde. 40 Outra iniciativa similar, enfocando os agentes comunitários de saúde está em fase final de elaboração pelo Ministério da Saúde. Apesar dessas importantes iniciativas, o serviço público de saúde ainda tem muito a caminhar. Países como Estados Unidos e Canadá estão atuando na direção da prevenção há mais de uma década, com resultados, que os dados comprovam, envolvendo famílias, bairros e conscientização da sociedade em geral.

Desta forma, seja a partir de ações específicas do setor saúde para prevenir e para tratar as consequiências da violência; seja na sua articulação interdisciplinar, interprofissional e multi-setorial, é importante ter em mente que nossas energias devem ser encaminhadas para a construção dos direitos humanos e sociais. Pois atuar contra as causas da violência significa atuar também contra a pobreza e a miséria que sacrificam nossos meninos e meninas e respeitar seus direitos consagrados na Constituição e no Estatuto da Criança e do Adolescente.

\section{Referências}

1. Vallès J. El niño. Barcelona: Bruguera; 1985.

2. Guerra VN. A. Violência física doméstica contra crianças e adolescentes e a imprensa: do silêncio à comunicação [tese doutorado]. São Paulo: Pontifícia Universidade Católica; 1996.

3. Assis SG. Crianças e adolescentes violentados: presente e perspectivas para o futuro. Cad Saúde Pública 1994; 10 Suppl 1: 126-34.

4. Deslandes SF. Atenção a criança e adolescentes vítimas de violência doméstica: análise de um serviço. Cad Saúde Pública 1994; 10 Suppl 1: 177-87.

5. Veyne P. O império romano. In: Arias P, Duby G., organizadores. História da vida privada. São Paulo: Companhia das Letras; 1992. v. 1, p. 19-224.

6. Bíblia. AT. Antigo Testamento. II Reis, cap. 6, vers. 26-29

7. De Mause L. The history of childhood. New York: Harper Torchbooks; 1975.

8. Bíblia. AT. Antigo Testamento. Deuteronômio, cap. 6, vers. $18-21$

9. Mc Laughin MM. Supervivientes y substitutos: hyjos y padres del siglo IX al siglo XIII. In: De Mause L., organizador. História de la infancia. Madrid: Alianza; 1982. p.121-205.

10. Badinter E. Um amor conquistado: o mito do amor materno. Rio de Janeiro: Nova Fronteira; 1985.

11. Hugo V. Os miseráveis. Rio de Janeiro: Ediouro; 1970

12. Ariès P. História social da criança e da família. Rio de Janeiro: Zahar; 1978

13. Minayo MCS, Souza ER. É possível prevenir a violência?
Reflexões a partir do campo da saúde pública. Rev Cienc Saúde Coletiva 1999; 4: 7-32.

14. IBGE. Instituto Brasileiro de Geografia e Estatística. Crianças e adolescentes: indicadores sociais. Rio de Janeiro: IBGE; 1997. v. 6

15. Carlson U, Von FC, organizadores. A criança e a violência na mídia. São Paulo: Cortez, 1999.

16. Minayo MCS, Assis SG, Souza ER, Njaine K, Deslandes F, Silva CMFP, Fraga PCP, Gomes R, Abramovay M, Waoseçfosz JJ, Monteiro MCN. Fala galera: juventude, violência e cidadania na cidade do Rio de Janeiro. Rio de Janeiro: Garamond; 1999.

17. Rizzini I, Pilotti F, organizadores. A arte de governar crianças. Rio de Janeiro: Amais, Santa Úrsula; 1996.

18. Minayo MCS, organizadora. O limite da exclusão social meninos e meninas de rua no Brasil. São Paulo: HUCITEC, Rio de Janeiro: ABRASCO; 1993.

19. Lusk MW. Street children of Rio de Janeiro. Utah, USA: Utah University; 1989. [mimeo]

20. IBGE. Instituto Brasileiro de Geografia e Estatística. Pesquisa nacional por amostra de domicílios: síntese de indicadores 1999. Rio de Janeiro: IBGE; 2000.

21. UNICEF. Fundo das Nações Unidas para a Infância. A infância brasileira nos anos 90. Brasília, DF: UNICEF, 1998.

22. Mateos SB. Nossas crianças, a sucata do progresso. Atenção 1995/1996; 1 (2).

23. Altoé S. Infâncias perdidas: o cotidiano nos internatos/prisão. Rio de Janeiro: Xenon; 1990 
24. Oliveira MB, Assis SG. Os adolescentes infratores do Rio de Janeiro e as instituições que os "ressocializam": a perpetuação do descaso. Cad Saúde Pública 1999; 15: 83144

25. Assis SG. Traçando caminhos em uma sociedade violenta: a vida de jovens infratores e seus irmãos não infratores. Rio de Janeiro: Fundação Oswaldo Cruz (FIOCRUZ); 1999

26. Assis SG, Constantino P. Filhas do mundo: infração juvenil feminina no Rio de Janeiro. Rio de Janeiro: Fundação Oswaldo Cruz (FIOCRUZ); 2000.

27. IBGE. Instituto Brasileiro de Geografia e Estatística. Crianças e adolescentes: indicadores sociais. Rio de Janeiro: IBGE; 1989.

28. Assis SG. Criança, violência e comportamento. Um estudo em grupos sociais distintos: relatório final de pesquisa Rio de Janeiro: Sociedade Brasileira de Pediatria (SBP), Centro Latino-Americano de Estudos sobre Violência e Saúde, (CLAVES.), Escola Nacional de Saúde Pública, (ENSP), Fundação Oswaldo Cruz (FIOCRUZ); 1992. [mimeo].

29. Moraes SRS. Perfil de crianças e adolescentes vítimas de violência doméstica [dissertação mestrado]. Rio de Janeiro: Universidade Federal; 1998.

30. Gomes R. A violência enquanto agravo à saúde de meninas que vivem nas ruas. Rio de Janeiro. Cad Saúde Pública 1994; 10 Suppl 1: 156-167.

31. CBCA. Centro Brasileiro da Criança e do Adolescente. Mortes por violência: pesquisa sobre violência contra crianças e adolescentes mulheres, 1987-1989. Recife: Casa de Passagem; 1991. [mimeo].

32. Saffioti $H$. No fio da navalha: violência contra crianças e adolescentes no Brasil atual. São Paulo: [s. n.]; 1993. [mimeo].

33. Ministério da Justiça. Departamento da criança e do adolescente. Atendimento ao adolescente em conflito com a lei: reflexões de uma prática qualificada. Brasília, DF: Ministério da Saúde; 1998. (Coleção Garantia de direitos. Série Idéias e resultados).

34. Volpi M, organizador. O adolescente e o ato infracional. São Paulo: Cortez; 1997.

35. Burke P. Violência e civilização. Braudel Papers 1995; (12): $1-8$
36. CEAP. Centro de Articulação de Populações Marginalizadas. Violência e racismo: relatório sobre o extermínio de crianças e adolescentes no Rio de Janeiro no ano de 1994. Rio de Janeiro: CEAP; 1996.

37. Rio de Janeiro [Estado]. Secretaria de Justiça. Segunda Vara da Infância e Juventude do Rio de Janeiro. Estatística 1999. Rio de Janeiro: Segunda Vara da Infância e Juventude da Secretaria de Justiça; 1999.

38. National Center on Child Abuse and Neglect. Data system. Ithaca, New York, USA. 1995. [mimeo]

39. Kempe RS, Kempe CH. Child abuse. Londres: Fontana Open Books; 1978.

40. Deslandes SF. Cotidiano dos serviços de emergência: representações, práticas, interações e desafios [tese doutorado]. Rio de Janeiro: Escola Nacional de Saúde Pública, Fundação Oswaldo Cruz (FIOCRZ); 2000.

41. SBP. Sociedade Brasileira de Pediatria, CLAVES. Centro Latino-Americano de Estudos sobre Violência e Saúde, FIOCRUZ. Fundação Oswaldo Cruz, Ministério da Justiça. Guia de atuação frente a maus tratos na infância e na adolescência: orientações para pediatras e profissionais de saúde. Rio de Janeiro: SBP; 2000.

42. Souza ER. Homicídios no Brasil: o grande vilão da saúde pública na década de 80. Cad Saúde Pública 1994; 10 Suppl 1: 45-60

43. Souza ER, Minayo MCS. Impacto da violência social na Saúde Pública: década de 80. In: Minayo MCS, organizadora. Os muitos Brasis. São Paulo: HUCITEC, Rio de Janeiro: Associação Brasileira de Pós-Graduação em Saúde Coletiva (ABRASCO); 1994.

44. Mello Jorge MHP. Investigação sobre a mortalidade por acidentes e violências na infância [tese livre-docência). São Paulo: Faculdade de Saúde Pública, Universidade de São Paulo; 1988.

45. Iunes R.F. Impacto econômico das causas externas no Brasil: esforço de mensuração. Rev Saúde Pública 1997; 31 Suppl 4: 38-46.

46. Deslandes SF. O impacto da violência na emergência hospitalar: relatório final de pesquisa. Rio de Janeiro: Centro Latino-Americano de Estudos sobre Violência e Saúde (CLAVES), Escola Nacional de Saúde Pública da Fundação Oswaldo Cruz (ENSP/FIOCRUZ); 1997. [mimeo]. 